\title{
Nitric oxide synthases in pregnant rat uterus
}

\author{
M. Farina, M. L. Ribeiro and A. Franchi* \\ Centro de Estudios Farmacológicos y Botánicos (CEFYBO), Consejo Nacional de \\ Investigaciones Científicas y Técnicas (CONICET), Serrano 669, Capital Federal, 1414, \\ Buenos Aires, Argentina
}

\begin{abstract}
The conversion of $\left[{ }^{14} \mathrm{C}\right]$ arginine into $\left[{ }^{14} \mathrm{C}\right]$ citrulline as an indicator of nitric oxide synthesis was studied in uteri isolated from rats on different days of gestation, after labour and during dioestrus. Nitric oxide synthesis was present in uterine tissues isolated at each stage of gestation and also in tissues collected during dioestrus and after labour. Expression of neuronal nitric oxide synthase was not detectable at any of the stages studied. Endothelial nitric oxide synthase was present at all the stages studied, but there was a significant increase on day 13 of gestation and a decrease thereafter, with the lowest expression recorded on the day after labour. Inducible nitric oxide
\end{abstract}

synthase expression in rat uteri increased substantially during pregnancy, with the highest expression on day 13 of gestation; expression decreased at term and after labour. The changes in expression of inducible nitric oxide synthase were coincident with the changes in nitric oxide synthase activity in uteri treated with aminoguanidine. Thus, these findings indicate that an increase in expression of inducible nitric oxide synthase in the uterus may be important for maintenance of uterine quiescence during pregnancy and its decrease near the time of labour could have an effect on the start of uterine contractility.

\section{Introduction}

Nitric oxide is an inorganic free radical gas that is well recognized as the principal mediator of several functions, including the relaxation of smooth muscles in a variety of tissues (Moncada et al., 1991).

Nitric oxide is generated from L-arginine by nitric oxide synthase. Multiple isoforms of this enzyme have been reported (Moncada and Higgs, 1993). Nerve fibres synthesizing nitric oxide have been demonstrated in the uteri of nonpregnant rats and mice by co-localization with NADPH diaphorase and by immunoreactivity using antibodies raised against pig and rat neuronal nitric oxide synthase and inducible nitric oxide synthase (Papka and McNeill, 1992; Grozdanovic et al., 1994; Suburo et al., 1995).

Nitric oxide regulates smooth muscle cell contractility and spontaneous contraction during the oestrous cycle, as well as distension of the uterus during pregnancy (Izumi and Garfield, 1995). The activity of nitric oxide synthase in maternal tissues increases early in pregnancy and an increased activity of nitric oxide synthase plays a role in adaptation of vascular and gastrointestinal muscle in guinea-pigs during this period (Weiner et al., 1994; Purcell et al., 1997). Nitric oxide has also been implicated in peripheral vasodilatation in pregnancy and in the control of blood flow in the fetoplacental circulation (Poston et al., 1995). Some studies have implicated a nitric oxide-cyclic

*Correspondence

afranchi@mail.retine.ar guanosine monophosphate relaxation pathway as responsible for maintaining uterine quiescence during pregnancy in humans and rats (Izumi et al., 1993; Buhimischi et al., 1995). Other studies demonstrated an increase in expression of inducible nitric oxide synthase mRNA in rat uteri and a minor increase in expression of endothelial nitric oxide synthase and neuronal nitric oxide synthase mRNA during late pregnancy (Ali et al., 1997; Dong et al., 1998). Riemer et al. (1997) used immunohistochemistry to show that there is expression of inducible nitric oxide synthase and endothelial nitric oxide synthase in myometrium on days 17-18 of pregnancy and that expression decreased at term in rats in labour. However, the production of nitric oxide in early, mid- and late pregnancy was not compared in these studies, so it is not known when nitric oxide synthesis starts to increase.

The aim of the present study was to examine: (i) the production of nitric oxide in uteri from pregnant rats at early, mid- and late pregnancy and after labour; and (ii) differences in the expression of different isoforms of nitric oxide synthase at the same stages of pregnancy.

\section{Materials and Methods}

\section{Drugs and chemicals}

Aminoguanidine, $\mathrm{N}^{\omega}{ }^{\omega}$-nitro-L-arginine methyl ester ( $\mathrm{L}$ NAME), $N^{\omega}$-nitro-D-arginine methyl ester (D-NAME) and L-valine were purchased from Sigma Chemical Co (St Louis, MO). $\left[{ }^{14} \mathrm{C}\right.$ ]arginine was purchased from Amersham Corporation (Arlington Heights, IL). Dowex AG 50WX8 cation exchange resin was obtained from Bio-Rad 
Laboratories (Alfatron, SRL, Buenos Aires). The western blotting reagents were obtained from Sigma and Bio-Rad Chemicals. The antibodies for western blotting were obtained from Transduction Laboratories (Lexington, KY). All other chemicals were analytical grade.

\section{Animals}

Time-mated pregnant rats of the Wistar strain (200-230 g body weight) were used. The rats were maintained on a $12 \mathrm{~h}$ light:12 $\mathrm{h}$ dark schedule. Animal chow and water were available ad libitum. Pregnant animals ( $n=6$ for each stage of pregnancy) were killed on different days of gestation (days 5, 13, 21 and 22) and 1 day after parturition. Spontaneous term labour typically occurred at night on day 22 of gestation (day 1: day on which a sperm plug was observed). Uterine tissue was also obtained from cyclic nonpregnant rats $(n=6)$ in dioestrus. All the animals were stunned by a blow on the neck. The uterus of each rat, containing both myometrium and endometrium, was removed immediately, cleaned of fat, placenta, fetuses, fetal membranes and blood vessels, and was rinsed thoroughly in cold Krebs' ringer bicarbonate buffer (KRB) for determination of nitric oxide synthase activity or extracted for western analysis.

\section{Conversion of $\left[{ }^{14} \mathrm{C}\right]$ arginine into $\left[{ }^{14} \mathrm{C}\right]$ citrulline}

The release of nitric oxide from incubated uterine strips was measured using the modified method of Bredt and Snyder (1989), which measures the conversion of $\left[{ }^{14} \mathrm{C}\right]$ arginine into $\left[{ }^{14} \mathrm{C}\right]$ citrulline, as citrulline remains in the sample, whereas the equimolar amounts of nitric oxide produced are rapidly destroyed.

Cross-sectional slices were cut from the centre of the uterus. The slices were incubated in a buffer that contained 20 mmol Hepes $\mathrm{I}^{-1}, 10 \mu \mathrm{mol}\left[{ }^{14} \mathrm{C}\right]$ arginine $\mathrm{I}^{-1}(0.3 \mu \mathrm{Ci})$ and

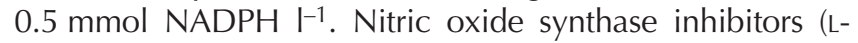
NAME or aminoguanidine) were added at this stage when required. Valine $\left(25 \mathrm{mmol} \mathrm{I}^{-1}\right)$, which inhibits the conversion of L-arginine into L-citrulline by arginases by $25-40 \%$ in uterine tissue, was included in the reaction mixture to increase assay specificity. The samples were homogenized after 15 min of incubation.

The samples were centrifuged for $10 \mathrm{~min}$ at $3000 \mathrm{~g}$ and applied to a $1 \mathrm{ml}$ DOWEX AG50W-X8 column $\left(\mathrm{Na}^{+}\right.$ form) and $\left[{ }^{14} \mathrm{C}\right]$ citrulline was eluted in $3 \mathrm{ml}$ water. The radioactivity was measured by liquid scintillation counting. Enzyme activity is reported as pmol $\left[{ }^{14} \mathrm{C}\right]$ citrulline $\left(15 \mathrm{~min}^{-1}(100 \mathrm{mg})^{-1}\right.$ wet weight.

\section{Electrophoresis and western blotting}

The uteri were homogenized in an Ultra-Turrax

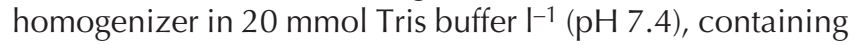
$0.25 \mathrm{mmol}$ sucrose $\mathrm{I}^{-1}$, EDTA $\left(1 \mathrm{mmol} \mathrm{I}^{-1}\right)$, phenylmethyl sulphonyl fluoride $\left(100 \mu \mathrm{g} \mathrm{ml}^{-1}\right)$, aprotinin $\left(10 \mu \mathrm{g} \mathrm{ml}^{-1}\right)$, leupeptin $\left(10 \mu \mathrm{g} \mathrm{m}^{-1}\right)$ and sorbean trypsin inhibitor $\left(10 \mu \mathrm{g} \mathrm{ml}^{-1}\right)$. After centrifugation at $7800 \mathrm{~g}$ for $10 \mathrm{~min}$, the supernatants were collected and stored at $-70^{\circ} \mathrm{C}$ until western blotting was performed. Each point represents pooled material from four animals. Seventy micrograms of protein were loaded in each lane. Positive control aliquots were also loaded. Membrane fraction of human endothelial cells was used for endothelial nitric oxide synthase, mouse macrophage lysate for inducible nitric oxide synthase and rat pituitary lysate for neuronal nitric oxide synthase (Transduction Laboratories, Lexington, KY). Samples were separated on a $7.5 \%(\mathrm{w} / \mathrm{v})$ sodium dodecyl sulphatepolyacrylamide gel by electrophoresis and transferred to a nitrocellulose membrane (Pharmacia Biotech, Sweden). The blots were incubated with a rabbit antiserum for $2 \mathrm{~h}$ at room temperature for anti-endothelial nitric oxide synthase, anti-inducible nitric oxide synthase and anti-neuronal nitric oxide synthase antibodies. All the primary antibodies were used at a final dilution of 1:1000 in the blocking buffer. The blots were washed with wash buffer $\left(10 \mathrm{mmol}\right.$ Tris $\mathrm{I}^{-1}$, $100 \mathrm{mmol} \mathrm{NaCl} \mathrm{I}^{-1}$ and $0.1 \%$ (v/v) Tween-20, $\mathrm{pH} 7.5$ ) followed by alkaline phosphatase-conjugated anti-rabbit $\lg \mathrm{G}$ as the secondary antibody and were developed with 5bromo-4-chloro-3-indolyl-phosphate toluidine Salt (BCIP) and nitroblue tetrazolium (NBT). Molecular weight markers were used to identify the protein bands. Photographs of the membranes were taken and they were densitometrically scanned and analysed using a Dekmate III scanner and Sigma Gel software package. The concentration of protein loaded in each lane was measured by the Bradford method (Bradford, 1976).

\section{Statistics}

Statistical significance was tested by Student-NewmanKeuls multiple comparison test for unequal replicates. The level of significance was $P<0.05$.

\section{Results}

\section{Conversion of $\left[{ }^{14} \mathrm{C}\right]$ arginine into $\left[{ }^{14} \mathrm{C}\right]$ citrulline}

Nitric oxide synthase activity was present in uterine tissues from each stage of gestation that was examined and also in tissues taken during dioestrus and after labour. Nitric oxide synthase activity was at a maximum at day 13 of gestation and at a minimum at day 22 of gestation and after labour (Fig. 1). The effects of L-NAME $\left(300 \mu \mathrm{mol} \mathrm{I}^{-1}\right)$, a competitive inhibitor of all nitric oxide synthase isoforms, and D-NAME (300 $\mu \mathrm{mol} \mathrm{I-1})$, an inactive enantiomer, were investigated on days 5,13 and 21 of pregnancy to determine whether citrulline production was related specifically to activity of nitric oxide synthases. L-NAME inhibited enzyme activity compared with control values on days 5, 13 and 21 of pregnancy by 45, 67 and 59\%, respectively (Fig. 2). DNAME was unable to inhibit nitric oxide synthase activity. The effect of aminoguanidine $\left(500 \mu \mathrm{mol} \mathrm{I}^{-1}\right)$, a selective inhibitor of inducible nitric oxide synthase (Misko et al., 1993), on nitric oxide production was also investigated on 


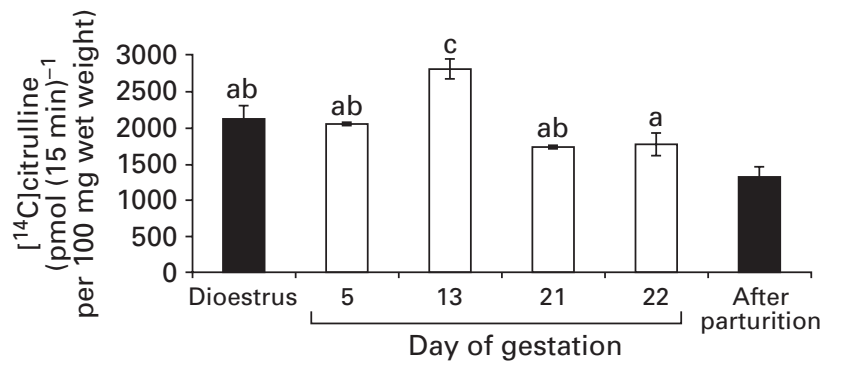

Fig. 1. Nitric oxide synthase activity in rat uterine tissue at different stages of pregnancy, during dioestrus (nonpregnant) and after

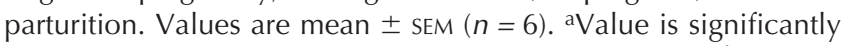
different from value at day 13 of gestation $(P<0.001)$. bValue is significantly different from value after parturition $(P<0.01)$. ${ }^{\mathrm{C}}$ Value is significantly different from value after parturition $(P<0.001)$.

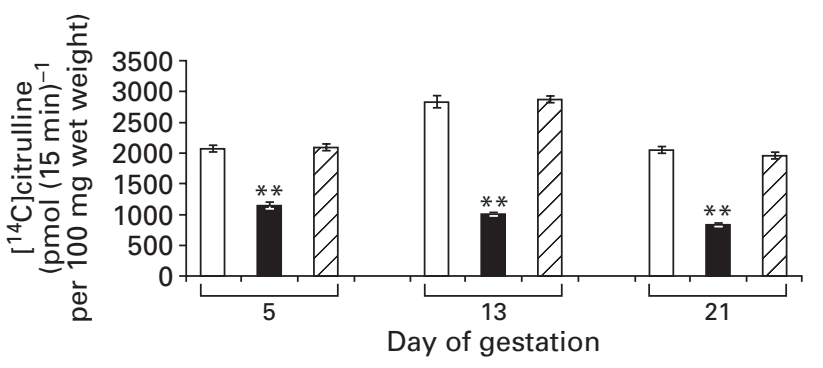

Fig. 2. Effect of a nitric oxide synthase inhibitor (L-NAME; $\mathbf{\square})$ and D-NAME $(\square)$ on nitric oxide synthase activity in rat uterine tissue at different stages of pregnancy. $\square$ : Control. Values are mean \pm SEM $(n=6)$. ${ }^{* *}$ Value is significantly different from corresponding control value $(P<0.01)$.

uterine tissues from the different stages. Aminoguanidine decreased nitric oxide synthase activity significantly in samples of nonpregnant dioestrous uterus and uterus collected on days 5 and 13 of pregnancy (Fig. 3); the presence of inducible nitric oxide synthase was examined in light of the observation that aminoguanidine decreased nitric oxide production in these states.

\section{Immunodetection of nitric oxide synthase proteins}

Western blotting was used to determine the presence of different nitric oxide synthase enzymes, to measure the amount of nitric oxide synthase proteins present in the uterus and to determine whether the proteins changed in a manner that correlated with the changes in activity. Neuronal nitric oxide synthase was not detected in western blots of uterine extracts in any of the states studied (Fig. 4). The monoclonal antibody to endothelial nitric oxide synthase reacted with the appropriate band corresponding to the $140 \mathrm{kDa}$ protein from the membrane fraction of human endothelial cells. A band at $140 \mathrm{kDa}$ corresponding

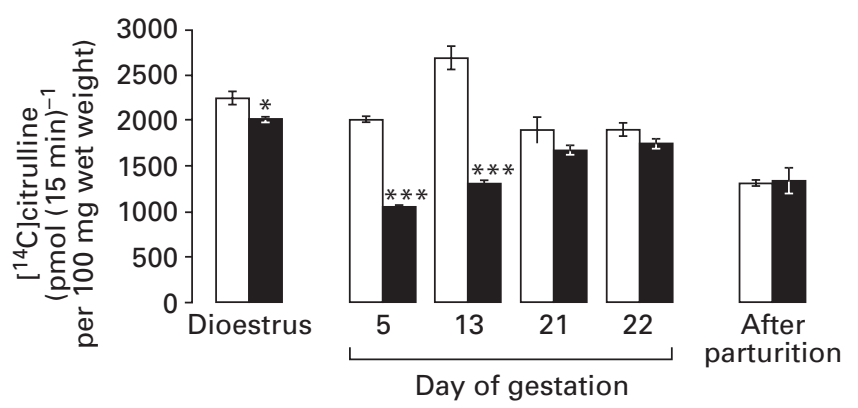

Fig. 3. Effect of an inducible nitric oxide synthase inhibitor (aminoguanidine; $\mathbf{\square}$ ) on nitric oxide synthase activity in rat uterine tissue at different stages of pregnancy, during dioestrus and after parturition. Values are mean $\pm \operatorname{SEM}(n=6)$. Values are significantly different from corresponding control $(\square)$ at $* P<0.05$ and ${ }^{* * *} P<0.001$.

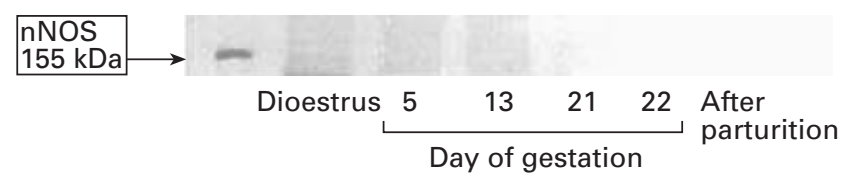

Fig. 4. Western blotting using a monoclonal antibody against neuronal nitric oxide synthase ( $\mathrm{nNOS}$ ) and uterine tissues collected at different stages of pregnancy (days 5, 13, 21 and 22), during dioestrus and after parturition. Each point represents a pool of four representative animals. Rat pituitary lysate was used as a positive control for neuronal nitric oxide synthase (Transduction Laboratories, Lexington, KY).

to the size of endothelial nitric oxide synthase was expressed at detectable levels in uteri from all the states studied (Fig. 5a). Densitometric analysis revealed that expression of endothelial nitric oxide synthase protein was high in nonpregnant dioestrous uterus and at day 13 of pregnancy, and that its expression was reduced in uteri collected at day 22 of pregnancy and after labour (Fig. $5 b)$. The monoclonal antibody to inducible nitric oxide synthase reacted with the band corresponding to $130 \mathrm{kDa}$. Expression of inducible nitric oxide synthase was detectable in uteri from nonpregnant dioestrous rats and uteri collected at days 5, 13 and 21 of gestation (Fig. 6a). Inducible nitric oxide synthase expression was not detected at day 22 of pregnancy or in uteri collected after labour. Densitometric analysis showed that expression of inducible nitric oxide synthase is at a maximum at day 13 of gestation (Fig. 6b).

\section{Discussion}

The results of the present study demonstrate the presence of inducible nitric oxide synthase and endothelial nitric oxide synthase, and nitric oxide synthase activity in pregnant and nonpregnant rat uteri. Conversion of arginine to citrulline 
(a)

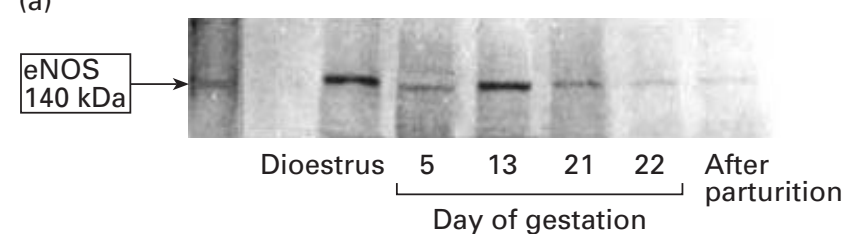

(b)

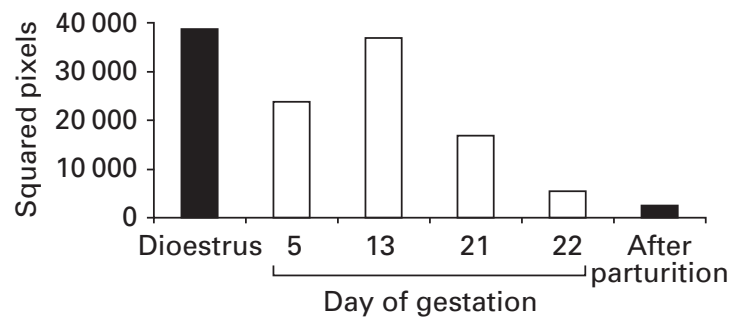

Fig. 5. (a) Western blotting using a monoclonal antibody against endothelial nitric oxide synthase (eNOS) and uterine tissues collected at different stages of pregnancy (days 5, 13, 21 and 22), during dioestrus and after parturition. Each point represents a pool of four representative animals. Human endothelial cells were used as a positive control for endothelial nitric oxide synthase. (b) Densitometric analysis was done with Sigma Gel.

(a)

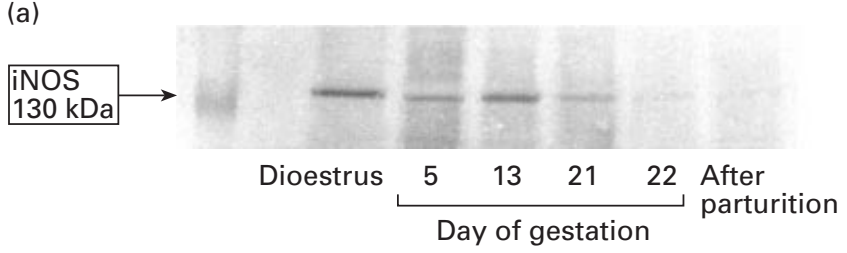

(b)

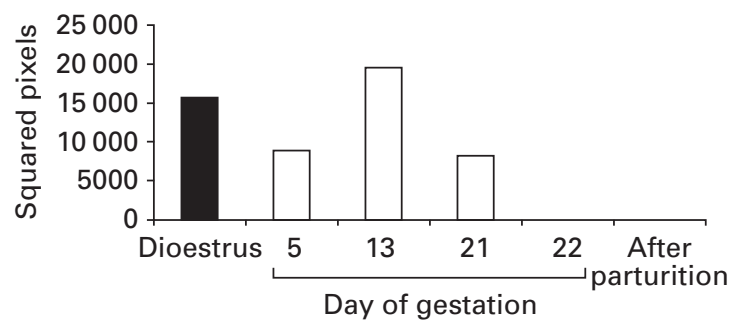

Fig. 6. (a) Western blotting using a monoclonal antibody against inducible nitric oxide synthase (iNOS) and uterine tissues collected at different stages of pregnancy (days 5, 13, 21 and 22), during dioestrus and after parturition. Each point represents a pool of four representative animals. Mouse macrophage lysate was used as positive control for inducible nitric oxide synthase. (b) Densitometric analysis was done with Sigma Gel.

was reduced by pre-incubation with L-NAME (a nitric oxide synthase inhibitor) but not by D-NAME (its inactive enantiomer). L-NAME inhibited enzyme activity by 45, 67 and $59 \%$ on days 5,13 and 21 , respectively. A high concentration of L-NAME $\left(600 \mu \mathrm{mol} \mathrm{I}^{-1}\right)$ reduced the conversion of arginine to citrulline by about $90 \%$ in rat uteri (data not shown).
Nitric oxide synthesis and the expression of isoforms of nitric oxide synthase during early, mid- and late pregnancy and after labour were also studied. Nitric oxide synthesis was at a maximum at day 13 of pregnancy and at a minimum on day 22 of pregnancy and after labour. Nitric oxide production augmented in the second part of pregnancy and the values of nitric oxide synthesized during the first part of pregnancy were similar to those of nonpregnant dioestrous uteri. Other studies have shown that generation of nitric oxide is upregulated during pregnancy and downregulated during delivery and after labour (Dong et al., 1996; Riemer et al., 1997). Neuronal nitric oxide synthase was not detected during pregnancy in the present study, thus supporting the results of Dong et al. (1996) and Buhimschi et al. (1996). These authors reported that neuronal nitric oxide synthase was detectable in the uterus of prepubertal rats and in nonpregnant adult rats. Suburo et al. (1995) used histochemical and immunohistochemical methods to demonstrate the presence of neuronal nitric oxide synthase in uteri from cyclic rats during dioestrus and metoestrus. However, in the present study, neuronal nitric oxide synthase was not detected in uteri collected during dioestrus or after labour. It is possible that the sensitivity of the antibody used was not sufficient to detect this protein. The absence of neuronal nitric oxide synthase during pregnancy could be attributed to degenerating nerves in the uterus during this stage (Stjernquist and Sjöberg, 1994). Immunostaining with two antisera against neuronal nitric oxide synthase yielded the same results, being strictly confined to nerve fibres (Suburo et al., 1995).

The effects of aminoguanidine (a selective inhibitor of inducible nitric oxide synthase activity) on nitric oxide production were also investigated in the present study. Aminoguanidine significantly decreased nitric oxide synthase activity in nonpregnant dioestrous uteri and in uteri collected on days 5 and 13 of pregnancy. The decrease in nitric oxide synthase activity induced by aminoguanidine parallel the changes in inducible nitric oxide synthase expression in all the states studied. Densitometric analysis showed that expression of inducible nitric oxide synthase was at a maximum at day 13 of gestation, but an inducible nitric oxide synthase band was detected on days 5 and 21 of pregnancy and in dioestrous uteri. However, even if we have observed an important expression of inducible nitric oxide synthase in dioestrus, there was only a slight inhibition of nitric oxide synthase activity by aminoguanidine in this state. Therefore, there is probably not a direct relationship between expression of inducible nitric oxide synthase and its activity during dioestrus. Perhaps the lack of activation of the enzyme could be attributed to absence of some cofactors or the presence of inhibitors.

Expression of endothelial nitric oxide synthase was high in nonpregnant dioestrous uteri and at day 13 of pregnancy, but it was also present, although in lower quantity, in uteri collected at day 22 of pregnancy and after labour. There were lower pregnancy-associated changes in nitric oxide synthesis of $\mathrm{Ca}^{2+}$-dependent nitric oxide synthase activity after treatment with aminoguanidine than changes in total 
nitric oxide synthase activity, indicating that this isoform may not be principally responsible for the changes in nitric oxide synthesis observed during pregnancy. This finding supports those of Dong et al. (1996) and Natuzzi et al. (1993), in which there were no significant pregnancy- associated changes in $\mathrm{Ca}^{2+}$-dependent nitric oxide synthase activity (activity of constitutive enzymes). Progesterone can augment the expression of inducible nitric oxide synthase and endothelial nitric oxide synthase in nonpregnant rat uteri (D. Ogando, M. Farina, M. L. Ribeiro, S. Perez Martinez, M. Cella, V. Rettori and A. Franchi, unpublished). This finding and the fact that expression of endothelial nitric oxide synthase and inducible nitric oxide synthase and nitric oxide synthesis are high when progesterone concentrations are also high during pregnancy may indicate that expression of inducible nitric oxide synthase may be regulated, at least partially, by progesterone. This conclusion is further supported by the study of Dong et al. (1996), in which the induction of preterm labour by the antiprogesterone RU486 was associated with an important decrease in inducible nitric oxide synthase expression.

In summary, the presence of inducible nitric oxide synthase and endothelial nitric oxide synthase protein in rat uteri has been demonstrated by western blotting. Expression of inducible nitric oxide synthase is increased during mid-pregnancy and is undetectable at the last day of pregnancy and after labour. Changes in endothelial nitric oxide synthase content (an increase on day 13 of pregnancy and a later decrease) were also observed, but this isoform is present during all stages of pregnancy and after labour. Nitric oxide synthase activity in aminoguanidine-treated rat uteri is decreased compared with control values during pregnancy and does not change after labour. These observations, together with previous studies showing that the blockade of nitric oxide synthase or removal of nitric oxide prevented the spontaneous decrease in uterine motility (Franchi et al., 1994) and with the findings of Izumi et al. (1993) demonstrating an L-arginine-nitric oxide system in rat myometrium that has an important role inhibiting uterine contractility, indicate that an increase in expression of inducible nitric oxide synthase in the uterus may be important in the maintenance of uterine quiescence during pregnancy and that a decrease in its activity is coincident with the beginning of the uterine contractions that are necessary for labour.

This work was supported by grant PICT 98, Proyecto 05-04426. The authors thank R. Morales and A. I. Casella for their technical assistance.

\section{References}

Ali M, Buhimschi I, Chwalisz K and Garfield R (1997) Changes in expression of the nitric oxide synthase isoforms in rat uterus and cervix during pregnancy and parturition Molecular Human Reproduction 3 995-1003

Bradford M (1976) A rapid and sensitive method for the quantitation of microgram quantities of protein utilizing the principle of protein-dye binding Analytical Biochemistry 72 246-254

Bredt DS and Snyder SH (1989) Nitric oxide mediates glutamate-linked enhancement of cGMP levels in the cerebellum Proceedings National Academy of Sciences USA 86 9030-9033
Buhimschi I, Yallampalli C, Dong Y-L and Garfield R (1995) Involvement of a nitric oxide-cyclic guanosine monophosphate pathway in control of human uterine contractility during pregnancy American Journal of Obstetrics and Gynecology 172 1577-1584

Buhimschi I, Ali M, Jain V, Chwalisz K and Garfield R (1996) Differential regulation of nitric oxide in the rat uterus and cervix during pregnancy and labour Human Reproduction 11 1755-1766

Dong Y-L, Gangula PRR and Yallampalli C (1996) Nitric oxide synthase isoforms in the rat uterus: differential regulation during pregnancy and labour Journal of Reproduction and Fertility 107 249-254

Dong Y-L, Fang L, Gangula PRR and Yallampalli C (1998) Regulation of inducible nitric oxide synthase messenger ribonucleic acid expression in pregnant rat uterus Biology of Reproduction 59 933-940

Franchi AM, Chaud M, Rettori V, Suburo A, McCann SM and Gimeno M (1994) Role of nitric oxide in eicosanoid synthesis and uterine motility in estrogen-treated rat uteri Proceedings National Academy of Sciences USA 91 539-543

Grozdanovic Z, Mayer B, Baumgarten HG and Bruning G (1994) Nitric oxide synthase- containing nerves fibers and neurons in the genital tract of the female mouse Cell Tissue Research 275 355-360

Izumi H and Garfield RE (1995) Relaxant effects of nitric oxide and cyclic GMP on pregnant rat uterine longitudinal smooth muscle European Journal of Obstetrics and Gynecology and Reproductive Biology 60 171-180

Izumi H, Yallampalli C and Garfield RE (1993) Gestational changes in Larginine-induced relaxation of pregnant rat and human myometrial smooth muscle American Journal of Obstetrics and Gynecology 169 $1327-1337$

Misko TP, Moore WM, Kasten TP, Nickols A, Corbett JA, Tilton RG, McDaniel ML, Williamson JR and Currie MG (1993) Selective inhibition of inducible nitric oxide synthase by aminoguanidine European Journal of Pharmacology 233 119-125

Moncada S and Higgs A (1993) The L-arginine-nitric oxide pathway New England Journal of Medicine 329 2002-2012

Moncada S, Palmer RMG and Higgs EA (1991) Nitric oxide: physiology, pathophysiology and pharmacology Pharmacological Reviews 43 109-142

Natuzzi ES, Ursell PC, Harrison M, Buscher C and Riemer RK (1993) Nitric oxide synthase activity in the pregnant uterus decreases at parturition Biochemical and Biophysical Research Communications 194 1-8

Papka RE and McNeill DL (1992) Distribution of NADPH-diaphorasepositive nerves in the uterine cervix and neurons in dorsal root and paracervical ganglia of the female rat Neuroscience Letters 147 224-228

Poston L, McCarthy AL and Ritter JM (1995) Control of vascular resistance in the maternal and feto-placental arterial beds Pharmacology and Therapeutics 65 215-239

Purcell TL, Buhimschi IA, Given R, Chwalisz K and Garfield RE (1997) Inducible nitric oxide synthase is present in the rat placenta at the fetal-maternal interface and decreases prior to labour Molecular Human Reproduction 3 485-491

Riemer RK, Buscher C, Bansal RK, Black SM, He Y and Natuzzi ES (1997) Increased expression of nitric oxide synthase in the myometrium of the pregnant rat uterus American Journal of Physiology 272 (Endocrinology and Metabolism 35) E1008-E1015

Stjernquist $\mathbf{M}$ and Sjöberg N-O (1994) Neurotransmitters in the myometrium. In The Uterus pp 193-229. Eds T Chard and JG Grudzinkas. Cambridge University Press, Cambridge

Suburo AM, Chaud M, Franchi A, Polak JM and Gimeno MAF (1995) Distribution of neuronal and non-neuronal NADPH diaphorase and nitric oxide synthases in rat uterine horns under different hormonal conditions Biology of Reproduction 52 631-637

Weiner CP, Lizasoain L, Baylis SA, Knowles RG, Charles IG and Moncada S (1994) Induction of calcium-dependent nitric oxide synthases by sex hormones Proceedings National Academy of Sciences USA 91 $5212-5216$

Received 16 May 2000.

Accepted 28 September 2000. 